\title{
REVISED Impact on carbon emissions of online study for a cohort
}

\section{of overseas students: A retrospective cohort study [version 3;}

\section{peer review: 2 approved, 1 approved with reservations]}

Previously titled: Comparing carbon emissions between online and in-person study for a cohort of overseas students: A retrospective cohort study

\author{
Richard F Heller (iD1, Ya-Yen Sun², Zhe Guo³, Arunima Malik \\ ${ }^{1}$ University of Newcastle, Newastle, NSW, Australia \\ ${ }^{2}$ UQ Business School, The University of Queensland, Brisbane, Queensland, Australia \\ ${ }^{3}$ The University of Sydney, Sydney, NSW, Australia \\ 4ISA, School of Physics and Accounting, Business School, University of Sydney, Sydney, NSW, Australia
}

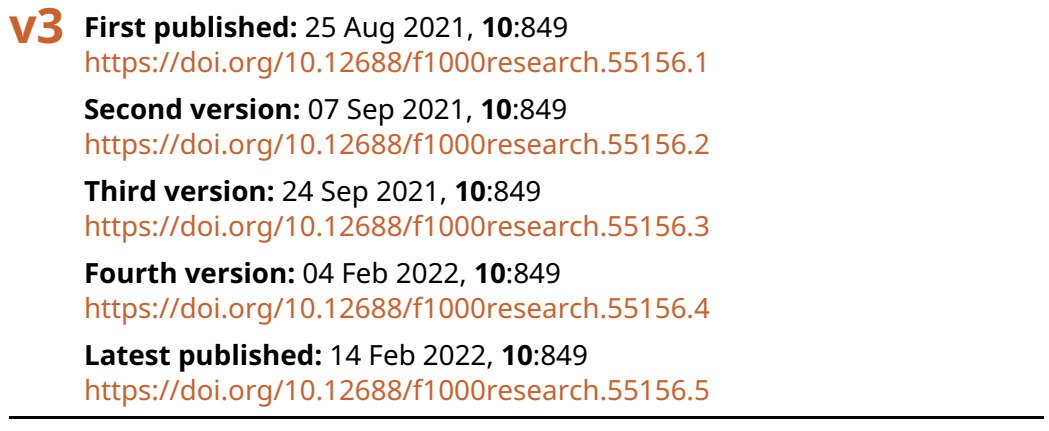

\section{Abstract}

Background: One of the benefits of online education is the potential reduction in carbon emissions through the decrease in travel to attend a university in person. We estimated the savings in $\mathrm{CO}_{2}$ emissions of an international cohort of master's students who studied fully online from their home countries, rather than travelling to the UK and living there while attending university.

Methods: The city and country of residence of a cohort of students who first enrolled in the fully online Peoples-uni/Manchester Metropolitan University MPH programme between the second semester of 2011 and the first semester 2013 were recorded. We estimated the aviation emissions between Manchester, UK and the cities where students reside, and subtracted the per capita emissions for the country of origin from the per capita emissions for the UK over the time that the student would have spent in Manchester as a fulltime student, based on the semester in which they first enrolled. Results: 128 students enrolled from 55 cities in 31 countries. 93 students were from a range of African countries and 18 from the Indian sub-continent. Flights to and from Manchester were estimated to have accounted for $114,553 \mathrm{~kg}$ of $\mathrm{CO}_{2}$ and living in Manchester for the duration of their course compared with staying in the home

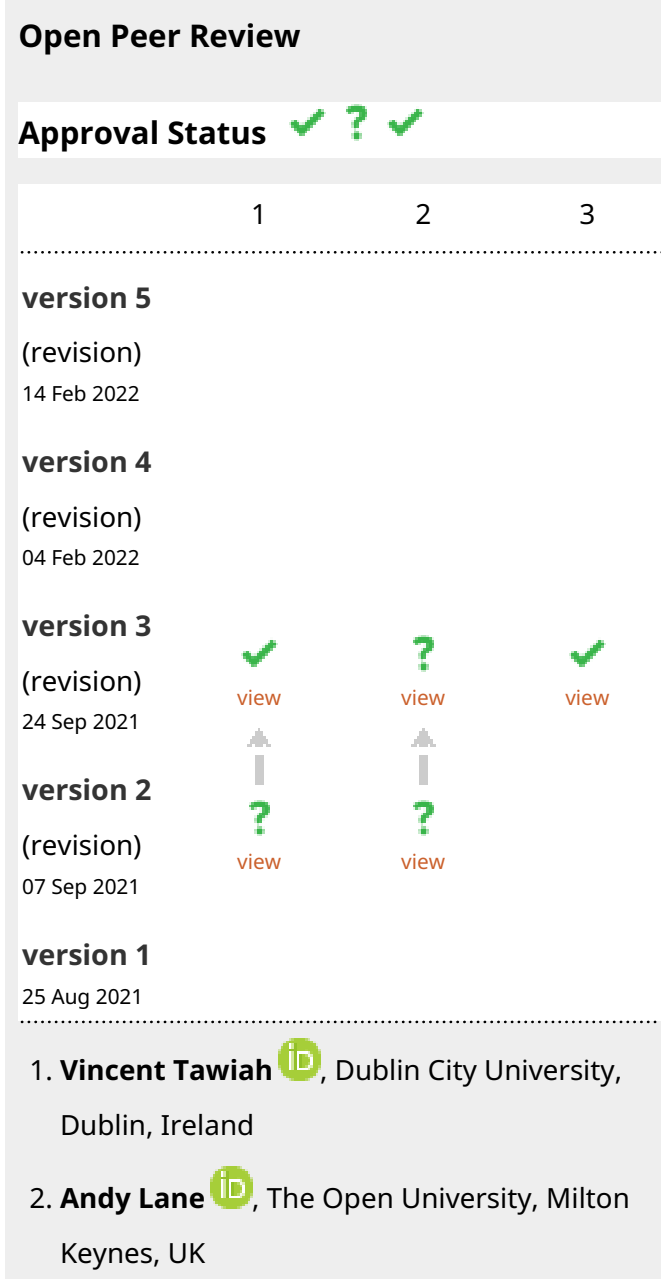


country would have been equivalent to $854,904 \mathrm{~kg}$ of $\mathrm{CO}_{2}$.

The combined net savings was $969,457 \mathrm{~kg}$ of $\mathrm{CO}_{2}$.

Conclusions: A small cohort of overseas students, largely from Africa and India, studied online rather than attending university in the UK. The likely saving by this small cohort of nearly a million $\mathrm{kg}$ of $\mathrm{CO}_{2}$ emissions offers an indication of the potential environmental benefits of offering university education online to overseas students.

Keywords

Online learning, carbon emissions, airline travel, overseas students
Sally Caird, The Open University, Milton

Keynes, UK

3. Geoffrey R Browne ID, University of

Melbourne, Melbourne, Australia

Any reports and responses or comments on the article can be found at the end of the article.

\section{Corresponding author: Richard F Heller (rfheller4@gmail.com)}

Author roles: Heller RF: Conceptualization, Data Curation, Methodology, Project Administration, Writing - Original Draft Preparation, Writing - Review \& Editing; Sun YY: Conceptualization, Data Curation, Formal Analysis, Methodology, Writing - Review \& Editing; Guo Z: Formal Analysis, Visualization, Writing - Review \& Editing; Malik A: Conceptualization, Data Curation, Formal Analysis, Methodology, Writing - Review \& Editing

Competing interests: No competing interests were disclosed.

Grant information: The author(s) declared that no grants were involved in supporting this work.

Copyright: $@ 2021$ Heller RF et al. This is an open access article distributed under the terms of the Creative Commons Attribution License , which permits unrestricted use, distribution, and reproduction in any medium, provided the original work is properly cited.

How to cite this article: Heller RF, Sun YY, Guo Z and Malik A. Impact on carbon emissions of online study for a cohort of overseas students: A retrospective cohort study [version 3; peer review: 2 approved, 1 approved with reservations] F1000Research 2021 , 10 :849 https://doi.org/10.12688/f1000research.55156.3

First published: 25 Aug 2021, 10:849 https://doi.org/10.12688/f1000research.55156.1 


\section{REVISED Amendments from Version 2}

We have made changes to the text and title to emphasise that we did not compare carbon emissions between different educational processes themselves, rather estimated the reduction in emissions from not travelling to and living in the UK to study. We have added references to the carbon footprint of universities and of wider international economic activities, and reflected on the relevance to the COVID era.

Any further responses from the reviewers can be found at the end of the article

\section{Background}

One of the benefits of online education is the potential reduction in carbon emissions through decreasing travel to attend university in person. Caird et al. ${ }^{1}$ calculated that among 15 higher education institutions in the UK, distance-based education models achieved an $83 \%$ reduction in carbon emissions, with the fully online model achieving the lowest carbon emissions. Estimates included travel, purchase and use of ICT devices, purchase of books and publications and use of paper for printing, residential and home energy use and campus site operations. Versteijlen et al. conclude: "The introduction of online education allows [...] a huge reduction in carbon emissions and could thus help HEIs [Higher Education Institutions] to achieve their energy efficiency and sustainability goals"2. However, there is little evidence in the existing literature that quantifies this potential for overseas students although one study reports that travel by overseas students to the university accounted for $6 \%$ of total emissions ${ }^{3}$ and another, while describing a large variation in estimated carbon emissions between different universities in Texas, also estimated the carbon emissions from travel through a 'study abroad' programme in one university ${ }^{4}$.

Peoples-uni, a volunteer led educational charity, provided fully online master's level courses to health professionals in low- to middle-income countries (LMICs) from 2008 to $2021^{5}$. For four semesters between 2011 and 2013, a partnership allowed students to enrol in the Master of Public Health (MPH) offered by Manchester Metropolitan University (MMU) by solely online study through the Peoples-uni without travel to the UK.

This paper estimates the savings in $\mathrm{CO}_{2}$ emissions by this cohort of students who studied fully online from their home countries rather than travelling to and living in Manchester to attend the University in-person.

\section{Methods}

A retrospective cohort study explored the records in the Peoplesuni database of each of the students who first enrolled through Peoples-uni in the MMU MPH award programme between the second semester of 2011 and the first semester of 2013. The city and country of residence were recorded, as was the final award gained. Even though the course was part-time, we assume that students would have been living in Manchester full-time and would have travelled by air from their home city. We assumed that they would have lived in Manchester for
18 months to complete a full 180 credit MPH, 12 months for those exiting with a 120 credit Graduate Diploma (passing all coursework except for the Dissertation) or 6 months for those exiting with a 60 credit Graduate Certificate (passing half the number of modules required for the Graduate Diploma). For students who passed some modules, but not enough to earn a Graduate Certificate, we assumed they would have spent 3 months in Manchester, and for those who passed no modules we assumed they would have withdrawn before travelling to Manchester. The dataset for this report can be found here ${ }^{6}$.

The differences of carbon emissions during participation in the MMU MPH programme are calculated as the following:

Net emissions $=$ (emissions of living in Manchester) - (emissions of living at home country) + round trip air transport emissions

If net emissions are larger than zero, this implies the online MMU MPH programme creates an environmental benefit with a carbon footprint at home smaller than the footprint when living in Manchester combined with the air travel.

To calculate the difference, we first used the International Civil Aviation Organization (ICAO) carbon emissions calculator? The ICAO provides the comprehensive city-pair carbon dioxide emissions from air travel by taking into account aircraft types, route specific data, passenger load factors and cargo carried. We estimated the aviation emissions between Manchester, UK and the city where students resided. To avoid overestimating the environmental impact of the travel, we took a conservative approach by choosing the route with fewest number of stops and lowest flight time or miles where this was an option, even though these may not have been the cheapest options, nor the actual flights used by the students. Road travel from a city without an international airport was recorded but not included in a calculation of emissions as the mode of travel was unknown and the estimates would have been imprecise.

To calculate the emissions of students living in the UK compared with their home country, the annual per capita $\mathrm{CO}_{2}$ emissions for each country were taken for the relevant years from data collected by the Carbon Dioxide Information Analysis Center and reported in OurWorldInData.org ${ }^{8}$. The per capita emissions for the country of origin were subtracted from the per capita emissions for the UK over the time that the student would have spent in Manchester as a full-time student, starting with the semester in which they first enrolled. We did not estimate the carbon emissions associated with different educational processes themselves.

\section{Ethics statement}

As part of the application process for entry to Peoples-uni courses, students were informed that their anonymised information might be used for research into the outcomes of the education programme. Data from the Peoples-uni database were extracted by one of the researchers (RFH) and de-identified by deleting the names of the students from the resulting spreadsheet shared for analysis with the other authors, and for the 
resulting publication. No ethical approval was sought due to the low-risk nature of the study.

\section{Results}

From 2011 to 2013, 128 students enrolled in the MMU MPH programme from 55 cities in 31 countries, 93 students were from Africa and 18 from the Indian sub-continent.

94 students gained an MPH, from which we recorded an assumed 18 months living in Manchester, 9 gained a Graduate Diploma, equating to 12 months in Manchester, and 16 students gained a Graduate Certificate, equating to 6 months in Manchester. 5 students passed two modules, corresponding to 3 months in Manchester, and 4 students gained no passes and are assumed not to have travelled to Manchester at all.

35 students started in the second semester of 2011, 24 and 22 respectively in the first and second semesters 2012, and 47 in the first semester of 2013. Although all students were from LMICs, some were living in high-income countries at the start of their studies.

\section{Transport emissions}

Two students started the MPH programme in the UK, so were not counted in the calculation of transport emissions. Flights to and from Manchester were estimated to have accounted for $114,553 \mathrm{~kg}$ of $\mathrm{CO}_{2}$ emissions, with an average of $924 \mathrm{~kg}$ per student. Transport emissions are largely determined by distance, and the largest emissions on flights were those flying intercontinental from Fiji $(2,133 \mathrm{~kg})$, Papua New Guinea $(1,635 \mathrm{~kg})$ and Zimbabwe $(1,495 \mathrm{~kg})$ to Manchester. Figure 1 shows the emissions for each country - where students came from more than one city in a country these were averaged to show country data.

\section{Emissions from living in Manchester}

The two students who enrolled from the UK had no change in emissions, and seven students came from countries (South Africa, USA, Canada and United Arab Emirates) with higher emissions than in the UK, so contributed negative counts. Overall, the emissions per capita are linked strongly to national economic development status - the higher the wealth the larger the emission footprint. Because the MMU MPH programme was mainly offered to students from LMICs, students' carbon footprint in their home country is generally lower than it would be living in Manchester, although this will vary over time. As examples, the net $\mathrm{CO}_{2}$ emission estimates used for 2013 were $7,354 \mathrm{~kg}$ for Manchester, $103 \mathrm{~kg}$ for Ethiopia and 72 for Rwanda. For the group as a whole, living in Manchester for the duration of their course compared with staying in the home country would have been equivalent to a net excess of $854,904 \mathrm{~kg}$ of $\mathrm{CO}_{2}$.

Combining transport and living gives an estimate of total excess net emissions of $969,457 \mathrm{~kg}$ of $\mathrm{CO}_{2}$. Figure 2 shows the total net emissions per country.

\section{Discussion}

This cohort of 128 master's students was estimated to have saved $969,457 \mathrm{~kg}$ of $\mathrm{CO}_{2}$ through studying online from their home country rather than travelling to and living in Manchester, UK to attend in person.

We used conservative assumptions for flight estimations in terms of number of stops and routes taken, and also assumed that the students travelled alone without family and did not return home during the programme. Flight emissions may reduce over time with increasing global attention to the climate change issue. Per capita emissions will also change over time in different ways across countries.

We have assumed that a student living in Manchester would have the same consumption patterns as the general population, and so created our method of calculating their consumption by subtracting the per capita $\mathrm{CO}_{2}$ emissions of their own country from that of the UK. It may be that students have lower consumption patterns than the general population, although the university campus has a high carbon footprint ${ }^{9,10}$. Caird et al. ${ }^{1}$

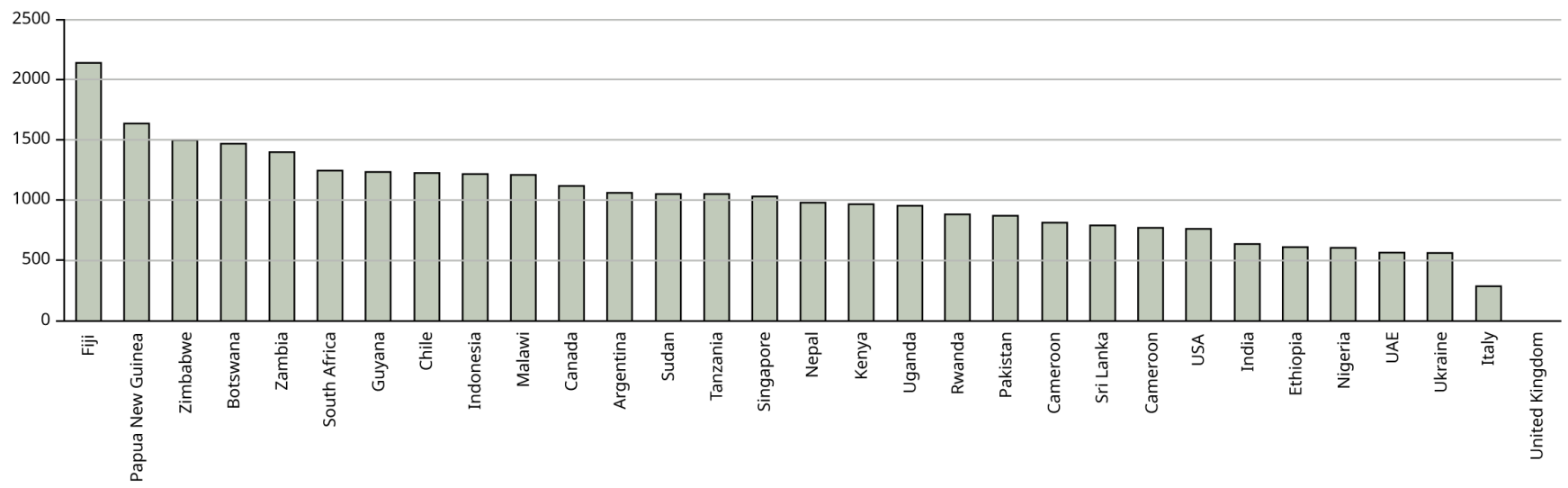

Figure 1. Mean emissions (in kg $\mathrm{CO}_{2}$ ) per country from air travel to Manchester and return. X axis shows the country from which the students come - where students come from more than one city in the country, the mean has been calculated to characterise the country. $\mathrm{Y}$ axis shows $\mathrm{kg} \mathrm{CO}$. 


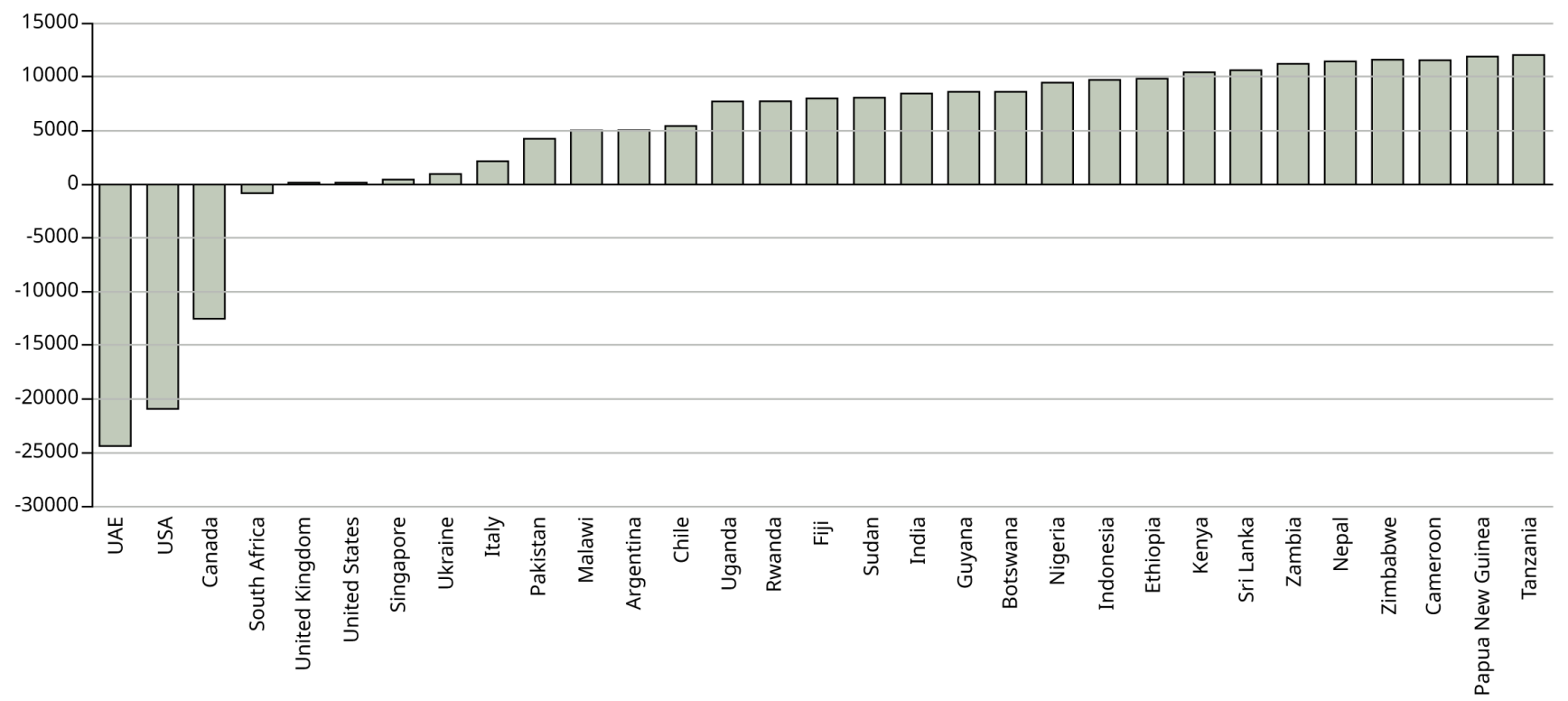

Figure 2. Difference in net emissions $\left(\mathrm{kg} \mathrm{CO}_{2}\right)$ between physical attendance in Manchester and studying online at home. $X$ axis shows the country from which the students come. $Y$ axis shows the net difference in emissions between the UK and each country in kg $\mathrm{CO}_{2}$

estimate $36 \mathrm{~kg} \mathrm{CO}_{2}$ per 100 study hours for UK based fully online courses (compared with $278 \mathrm{~kg}$ for face-to-face teaching). Applying this estimate for online teaching to our cohort would equate to $648 \mathrm{~kg}$ over the course of the master's degree, and $68,796 \mathrm{~kg}$ for the whole cohort. However, it is difficult to apply this to Peoples-uni which did not have a campus, used Open Educational Resources and whose students live in LMICs. Future research could consider specific supply chain aspects for quantifying reductions in emissions from online learning relating to students from LMICs. To this end, a global multi-regional input-output model could be integrated with detailed information on expenditure patterns of students on a country-by-country basis for quantifying their at-home carbon footprint, and the footprint if they travelled to the UK. Such an analysis could be performed at a sector-level, enabling the quantification of hotspots. Future work could also focus on expanding such an assessment to university-wide quantification of emission savings from online learning, beyond the assessed master's programme in this work, to provide an accurate estimate of the emissions from different teaching models related to the 'export' of higher education to LMIC populations. A university-wide assessment could also include savings through online working of the teaching staff, a possible decrease in electricity consumption in lecture theatres (and possible increase from students' perspective). Future research could also consider the costs associated with the sourcing of equipment for accessing online material, such as laptops, internet plans, and associated carbon emissions.

\section{Conclusion}

Project Atlas, quoting UNESCO data, estimated in their 2020 report that there were more than 5.6 million higher education students globally that were studying abroad ${ }^{11}$. In each of the top three countries receiving overseas students, the United States, the United Kingdom and Canada, more than $20 \%$ of all students were international. In the UK in 2019/20 there were more than 250,000 postgraduate non-UK students, the majority from outside the $\mathrm{EU}^{12}$. Considering that the countries from which most overseas students come have lower emissions per capita, having international students enrolled in in-person programmes will create a net emission increase compared with online-study. Given the large number of overseas students globally, their impact on carbon emissions is considerable.

There is a literature on the way in which numerous international economic activities affect the environment ${ }^{13,14}$ and the importance of international education to the economy of many countries demonstrates the value of considering how online education might contribute to a reduction in global $\mathrm{CO}_{2}$ emissions.

The benefits of reducing $\mathrm{CO}_{2}$ emissions through online education for international students should be seen in the context of the COVID era, which has demonstrated the importance of online education and the limits to international travel. That even a small cohort of international students, largely from Africa and India, studying online rather than travelling to the UK likely saved nearly a million $\mathrm{kg}$ of $\mathrm{CO}_{2}$ provides an indication of the extent of the savings that could be made through the development of online education for overseas students.

\section{Data availability}

Underlying data

Data come from International Civil Aviation Organization (ICAO) carbon emissions calculator ${ }^{7}$ https://www.icao.int/environmental-protection/CarbonOffset/Pages/default.aspx; and $\mathrm{CO}_{2}$ and 
Greenhouse Gas Emissions ${ }^{8}$ https://ourworldindata.org/co2-andother-greenhouse-gas-emissions

Zenodo: Saving carbon emissions through online learning for overseas students [Data set] https://doi.org/10.5281/zenodo. $5335866^{6}$
This project contains the following underlying data:

Student data and calculations, and $\mathrm{CO}_{2}$ emissions data

Data are available under the terms of the Creative Commons Attribution 4.0 International license (CC-BY 4.0).
1. Caird S, Lane A, Swithenby E, et al.: Design of higher education teaching models and carbon impacts. Int J Sust Higher Ed. 2015; 16(1): 96-111. Publisher Full Text

2. Versteijlen M, Salgado FP, Groesbeek MJ, et al.: Pros and cons of online education as a measure to reduce carbon emissions in higher education in the Netherlands. Curr Opin Environ Sustain. 2017; 28: 80-89. Publisher Full Text

3. Ozawa-Meida L, Brockway $\mathrm{P}$, Letten $\mathrm{K}$, et al.: Measuring carbon performance in a UK University through a consumption-based carbon footprint: De Montfort University case study. J Clean Prod. 2013; 56: 185-198. Publisher Full Text

4. Bailey G, LaPoint T: Comparing Greenhouse Gas Emissions across Texas Universities. Sustainability. 2016; 8(1): 80. Publisher Full Text

5. Heller RF, Strobl J, Madhok R: Online Education for Public Health Capacity Building in Low- to Middle-Income Countries: The Peoples-uni Experience. IRRODL. 2019; 20(1).

Publisher Full Text

6. Heller RF: Saving carbon emissions through online learning for overseas students [Data set]. Zenodo.

http://www.doi.org/10.5281/zenodo.5335866

7. International Civil Aviation Organization (ICAO) carbon emissions calculator. Reference Source
8. Ritchie $\mathrm{H}$, Roser M: $\mathrm{CO}_{2}$ and Greenhouse Gas Emissions. 2020. Reference Source

9. Yañez P, Sinha A, Vásquez M: Carbon Footprint Estimation in a University Campus: Evaluation and Insights. Sustainability. 2020; 12(1): 181. Publisher Full Text

10. Helmers E, Chang CC, Dauwels J: Carbon footprinting of universities worldwide: Part I-objective comparison by standardized metrics. Environ Sci Eur. 2021; 33: 30 Publisher Full Text

11. Institute of International Education: Project Atlas. 2021. Reference Source

12. HESA, the Higher Education Statistics Agency: Higher Education Student Statistics: UK, 2019/20 - Where students come from and go to study. 2021. Reference Source

13. Tawiah VK, Zakari A, Khan I: The environmental footprint of China-Africa engagement: An analysis of the effect of China - Africa partnership on carbon emissions. Sci Total Environ. 2021; 756: 143603. PubMed Abstract | Publisher Full Text

14. Li G, Zakari A, Tawiah V: Energy resource melioration and $\mathrm{CO}_{2}$ emissions in China and Nigeria: Efficiency and trade perspectives. Resources Policy. 2020; 68. 101769.

Reference Source 


\section{Open Peer Review}

\section{Current Peer Review Status:}

\section{Version 3}

Reviewer Report 17 January 2022

https://doi.org/10.5256/f1000research.77856.r119728

(C) 2022 Browne G. This is an open access peer review report distributed under the terms of the Creative Commons Attribution License, which permits unrestricted use, distribution, and reproduction in any medium, provided the original work is properly cited.

\section{Geoffrey R Browne}

Melbourne School of Design, University of Melbourne, Melbourne, Vic, Australia

This is a concise paper about a neat study that estimates, under conditions of limited data and therefore some reasonable assumptions, the emission reductions attributable to online as opposed to face to face learning, made up of 1) flights and 2) cost of living emissions attributable to a country's systems. Generally, online learning resulted in a reduction in emissions attributable to the cohort, with some variety in this depending on students' home country.

The limitations are explicit, which for such a study is important, and the findings have verisimilitude. Most of my comments take a broader picture which if the authors decide to use, could round out the article nicely, For example:

Despite the very important emissions benefit of online learning, there is likely to be an academic, social, and cultural benefit to international travel for these MPH students which has been forgone due to COVID-19. My own experience teaching in an online MPH (and other masters) is that for some students, there is lower engagement and possibly poorer academic performance. If the authors have experience or evidence of this that they could mention briefly, I feel it would round out the paper nicely.

\section{ABSTRACT}

'MPH' should be expanded in the first instance.

Methods: This part is currently oddly written and unclear about what you did. Important to get this right in the Abstract. It reads as though you estimated emissions attributable to flights, but then ignored these and then subtracted per capita emissions attributable to living in the UK while (Cf. 'over the time'?) studying from per capita emissions of the country of origin. This is incorrect so you need to clarify this. How about this? "Total difference in emissions was calculated by adding the estimated aviation emissions between Manchester, UK and the cities where students resided, to the difference in per capita emissions (generally a reduction) between the country of origin and the UK for the time that the student would have spent in Manchester, based on the semester in which they first enrolled.". 
Also, the authors might find the word 'attributable' useful when redrafting, it can be a more efficient way of communicating exactly what you are including in your estimates. For example, "To calculate the emissions of students living in the UK compared with their home country..." can be improved by writing, "To calculate the emissions attributable to students living in the UK instead of their home country...".

METHODS; data sources

No inferential statistical analyses were performed.

Overall, methods seem sound. I am not an expert in the details of carbon accounting, specifically, whether databases like International Civil Aviation Organization (ICAO) carbon emissions calculator and OurWorldInData.org (is this the 'original' source?) are the best sources. They seem reputable but I will leave this to others to review.

RESULTS

Re: "Overall, the emissions per capita are linked strongly to national economic development status - the higher the wealth the larger the emission footprint." It is great that the authors make this explicit. I'd like to see a bit more on this; a statement that makes it clear that the systems within which live significantly determine the $p / c$ emissions that are attributable to us, and so it is systems change, rather than individual behaviour change, that is needed, and that systems change is an issue of international ethical responsibility for people in power, rather than preventing or limiting international students from benefiting from the in-person educational opportunities provided in the global north (not that you are recommending this, but it could be read that way). This might be a good point for the conclusion.

\section{DISCUSSION}

Re: "flight emissions may reduce over time with increasing global attention to the climate change issue". I suggest you say very briefly (like, a few words only) what the mechanism might be: technological increases in aircraft efficiency? Aircraft emission standards? Also, please note that such tech and policy changes have not yet made any notable difference to total global emissions, probably due to the 'Jevons Paradox'.

Is the work clearly and accurately presented and does it cite the current literature? Partly

Is the study design appropriate and is the work technically sound? Yes

Are sufficient details of methods and analysis provided to allow replication by others? Partly

If applicable, is the statistical analysis and its interpretation appropriate? Not applicable

Are all the source data underlying the results available to ensure full reproducibility? 
Yes

Are the conclusions drawn adequately supported by the results?

Yes

Competing Interests: No competing interests were disclosed.

Reviewer Expertise: Sustainability, urban planning, public health, pedagogy

I confirm that I have read this submission and believe that I have an appropriate level of expertise to confirm that it is of an acceptable scientific standard.

Author Response 18 Jan 2022

Richard F Heller, University of Newastle, Newastle, Australia

Thank you for this review. We have submitted a revised version of the paper incorporating each of your suggestions.

Competing Interests: No competing interests were disclosed.

Reviewer Report 04 October 2021

https://doi.org/10.5256/f1000research.77856.r95409

(C) 2021 Lane A et al. This is an open access peer review report distributed under the terms of the Creative Commons Attribution License, which permits unrestricted use, distribution, and reproduction in any medium, provided the original work is properly cited.

\section{Andy Lane}

The Open University, Milton Keynes, UK

\section{Sally Caird}

School of Engineering and Innovation, Faculty of Science, Technology, Engineering and Maths, The Open University, Milton Keynes, UK

We do not feel inclined to change our assessment despite the changes made.

The authors have responded to most of our criticisms but do not go as far as openly admitting it is purely about travel impacts that just happen to be applied to an HE case. Equally, I feel that the authors have misrepresented our critique when they say:

"We have also added the following to the Discussion: "Caird et al. 1 estimate $36 \mathrm{~kg}$ CO2 per 100 study hours for UK based fully online courses (compared with $278 \mathrm{~kg}$ for face-to-face teaching). Applying this estimate for online teaching to our cohort would equate to $648 \mathrm{~kg}$ over the course of the master's degree, and 68,796kg for the whole cohort. However, it is difficult to apply this to Peoples-uni which did not have a campus, used Open Educational Resources and whose students live in LMICs." 
First, this does not acknowledge that our data only had a few international students in it so travel impacts were less than for their study, while this statement still persists in drawing a very tight boundary around what is included in the calculations. Peoples-uni might not have a campus but the people involved in running the course have residential impacts while the course was on the University of Manchester books and that has campus-based impacts, and producing OERs has impacts.

Is the work clearly and accurately presented and does it cite the current literature? Yes

Is the study design appropriate and is the work technically sound? Yes

Are sufficient details of methods and analysis provided to allow replication by others? Yes

If applicable, is the statistical analysis and its interpretation appropriate?

Yes

Are all the source data underlying the results available to ensure full reproducibility? Yes

Are the conclusions drawn adequately supported by the results?

Yes

Competing Interests: No competing interests were disclosed.

We confirm that we have read this submission and believe that we have an appropriate level of expertise to confirm that it is of an acceptable scientific standard, however we have significant reservations, as outlined above.

Author Response 06 Oct 2021

Richard F Heller, University of Newastle, Newastle, Australia

We are disappointed that the reviewers do not feel that our extensive revisions have met their initial reservations, as we agreed with the thrust of their comments and attempted to meet them responsibly. We are confused by the statement by the reviewers that we "...do not go as far as openly admitting it is purely about travel impacts that just happen to be applied to an HE case". In fact, as the reviewers note in their summary of our methods in their initial review, it is more than travel, as the students who travel to the UK have to live there, mostly for 18 months, during which time their carbon emissions are higher than they would have been if they had stayed in their home countries. This is related to their living, transport, and consumption patterns. We said "We have assumed that a student living in Manchester would have the same consumption patterns as the general population, and so created our method of calculating their consumption by subtracting the per capita $\mathrm{CO}_{2}$ emissions of their own country 
from that of the UK. It may be that students have lower consumption patterns than the general population, although the university campus has a high carbon footprint $9 \cdot 10$ ". We believe that we have been very clear in adding to the Methods section that "We did not estimate the carbon emissions associated with different educational processes themselves." and the first sentence of the Discussion states: "This cohort of 128 master's students was estimated to have saved $969,457 \mathrm{~kg}$ of $\mathrm{CO}_{2}$ through studying online from their home country rather than travelling to and living in Manchester, UK to attend in person."

In the Discussion, we have also extensively listed the requirements of a future more detailed study than in this brief report to take into account the additional specific emissions related to higher education: "Future work could also focus on expanding such an assessment to university-wide quantification of emission savings from online learning, beyond the assessed master's programme in this work, to provide an accurate estimate of the emissions from different teaching models related to the 'export' of higher education to LMIC populations.".

We are surprised by the reviewers' second suggestion that we "have misrepresented our critique". Our intention was to acknowledge the published work of the reviewers by a direct quote from their study to show that it is possible to calculate the detailed impact of the higher education environment on carbon emissions, but to say that this result could not be applied directly to our situation both due to the special nature of our educational process and to the fact that students came from LMICs. This was to link to the addition of details we had included in the Background about the Caird et al. study and set the scene for the future work as described above.

We hope that the reviewers might reconsider their assessment of our revisions.

Competing Interests: No competing interests were disclosed.

Reviewer Report 24 September 2021

https://doi.org/10.5256/f1000research.77856.r95408

(c) 2021 Tawiah V. This is an open access peer review report distributed under the terms of the Creative Commons Attribution License, which permits unrestricted use, distribution, and reproduction in any medium, provided the original work is properly cited.

\section{Vincent Tawiah}

DCU Business School, Dublin City University, Dublin, Ireland

The paper is okay for indexing.

Is the work clearly and accurately presented and does it cite the current literature? Yes

Is the study design appropriate and is the work technically sound? 
Yes

Are sufficient details of methods and analysis provided to allow replication by others? Yes

If applicable, is the statistical analysis and its interpretation appropriate?

Yes

Are all the source data underlying the results available to ensure full reproducibility?

Yes

Are the conclusions drawn adequately supported by the results?

Yes

Competing Interests: No competing interests were disclosed.

Reviewer Expertise: Climate change

I confirm that I have read this submission and believe that I have an appropriate level of expertise to confirm that it is of an acceptable scientific standard.

\section{Version 2}

Reviewer Report 15 September 2021

https://doi.org/10.5256/f1000research.77395.r93060

(c) 2021 Lane A et al. This is an open access peer review report distributed under the terms of the Creative Commons Attribution License, which permits unrestricted use, distribution, and reproduction in any medium, provided the original work is properly cited.

\section{Andy Lane}

The Open University, Milton Keynes, UK

\section{Sally Caird}

School of Engineering and Innovation, Faculty of Science, Technology, Engineering and Maths, The Open University, Milton Keynes, UK

The introduction is quite poor in setting the context. Some material in the conclusions should be in the introduction, for example, the discussion of Caird S, Lane A, Swithenby E, et al.: Design of higher education teaching models and carbon impacts. Int J Sust Higher Ed. 2015; 16(1): 96-111 1 would help with that context rather than being an afterthought in the conclusions.

The method used in this study is very high level and crude. It ignores the HE context (in terms of HE systems, climate action and sustainability policies and GHG emissions data) and does not describe the two teaching models compared; so consequently, it offers no insights into systemic 
aspects of HE institutional systems and teaching models. In other words, the method would be no different if it were calculating the effects of visiting the UK on holidays or for work for the same duration, and so it offers limited insight from a HE perspective. The title is therefore misleading because it does not look at the impacts of 'online and in-person study', instead, it estimates the impact of air travel of overseas students.

As far as we can tell, limited primary data was collected, other than on the number of students on a programme, their nationality, and their qualification programme. The method does not take student or staff activities related to teaching and learning into account, other than to make assumptions on average behaviours rather than any self-reporting of 'actual' behaviours. The study assumes:

students living in Manchester would have the same consumption patterns as the general population in the UK (is there no variation in consumption within countries?);

students would have been living in Manchester full-time;

the length of time students would have lived in Manchester, based on the time needed to complete their qualification programmes;

students would have travelled by air from their home city;

flight impacts in terms of the number of stops and routes taken;

students travelled alone without family and did not return home during the programme.

These limitations should be acknowledged, i.e. the study does not consider HE systems nor students specifically, and so the study is just an estimation of travel emissions related to visitors to the UK for a specific period of time.

\section{References}

1. Caird S, Lane A, Swithenby E, Roy R, et al.: Design of higher education teaching models and carbon impacts. International Journal of Sustainability in Higher Education. 2015; 16 (1): 96-111

Publisher Full Text

Is the work clearly and accurately presented and does it cite the current literature? Partly

Is the study design appropriate and is the work technically sound? Partly

Are sufficient details of methods and analysis provided to allow replication by others? Yes

If applicable, is the statistical analysis and its interpretation appropriate? Partly

Are all the source data underlying the results available to ensure full reproducibility? Partly 
Are the conclusions drawn adequately supported by the results?

Partly

Competing Interests: No competing interests were disclosed.

Reviewer Expertise: Environmental systems, innovation

We confirm that we have read this submission and believe that we have an appropriate level of expertise to confirm that it is of an acceptable scientific standard, however we have significant reservations, as outlined above.

Author Response 21 Sep 2021

Richard F Heller, University of Newastle, Newastle, Australia

Reviewer Report

Andy Lane, The Open University, Milton Keynes, UK

Sally Caird, The Open University, Milton Keynes, UK

The introduction is quite poor in setting the context. Some material in the conclusions should be in the introduction, for example, the discussion of Caird S, Lane A, Swithenby E, et al.: Design of higher education teaching models and carbon impacts. Int J Sust Higher Ed. 2015; 16(1): 96-1111 would help with that context rather than being an afterthought in the conclusions.

Author response: We have quoted this paper at the start of the Background which now reads as follows: "One of the benefits of online education is the potential reduction in carbon emissions through decreasing travel to attend university in person. Caird et al. 1 calculated that among 15 higher education institutions in the UK, distance-based education models achieved an 83\% reduction in carbon emissions, with the fully online model achieving the lowest carbon emissions. Estimates included travel, purchase and use of ICT devices, purchase of books and publications and use of paper for printing, residential and home energy use and campus site operations. Versteijlen et al. conclude: "The introduction of online education allows [...] a huge reduction in carbon emissions and could thus help HEIs [Higher Education Institutions] to achieve their energy efficiency and sustainability goals" 2"

The method used in this study is very high level and crude. It ignores the HE context (in terms of HE systems, climate action and sustainability policies and GHG emissions data) and does not describe the two teaching models compared; so consequently, it offers no insights into systemic aspects of HE institutional systems and teaching models. In other words, the method would be no different if it were calculating the effects of visiting the UK on holidays or for work for the same duration, and so it offers limited insight from a HE perspective. The title is therefore misleading because it does not look at the impacts of 'online and in-person study', instead, it estimates the impact of air travel of overseas students.

Author response: To reflect this comment we have changed the title as follows: "Impact on carbon emissions of online study for a cohort of overseas students: A retrospective cohort study". 
We have also added to the Methods the following: "We did not estimate the carbon emissions associated with different educational processes themselves."

We have also added the following to the Discussion: "Caird et al. 1 estimate $36 \mathrm{~kg}$ CO2 per 100 study hours for UK based fully online courses (compared with $278 \mathrm{~kg}$ for face-to-face teaching). Applying this estimate for online teaching to our cohort would equate to $648 \mathrm{~kg}$ over the course of the master's degree, and $68,796 \mathrm{~kg}$ for the whole cohort. However, it is difficult to apply this to Peoples-uni which did not have a campus, used Open Educational Resources and whose students live in LMICs."

We have also added to our original sentence in the Discussion "Future work could also focus on expanding such an assessment to university-wide quantification of emission savings from online learning, beyond the assessed master's programme in this work." which now reads: "Future work could also focus on expanding such an assessment to university-wide quantification of emission savings from online learning, beyond the assessed master's programme in this work, to provide a $n$ accurate estimate of the emissions from different teaching models related to the 'export' of higher education to LMIC populations."

We have also changed the final sentence in the Abstract from "The saving by this small cohort of nearly a million $\mathrm{kg}$ of $\mathrm{CO} 2$ emissions through not attending university in person offers an indication of the potential environmental benefits of offering university education online to overseas students." to "The likely saving by this small cohort of nearly a million kg of $\mathrm{CO} 2$ emissions offers an indication of the potential environmental benefits of offering university education online to overseas students."

As far as we can tell, limited primary data was collected, other than on the number of students on a programme, their nationality, and their qualification programme. The method does not take student or staff activities related to teaching and learning into account, other than to make assumptions on average behaviours rather than any self-reporting of 'actual' behaviours. The study assumes:

students living in Manchester would have the same consumption patterns as the general population in the UK (is there no variation in consumption within countries?); students would have been living in Manchester full-time;

the length of time students would have lived in Manchester, based on the time needed to complete their qualification programmes;

students would have travelled by air from their home city;

flight impacts in terms of the number of stops and routes taken;

students travelled alone without family and did not return home during the programme.

These limitations should be acknowledged, i.e. the study does not consider HE systems nor students specifically, and so the study is just an estimation of travel emissions related to visitors to the UK for a specific period of time.

Author response: We thank the Reviewers for these suggestions which clarify the nature of the study. As indicated above, we have now acknowledged the limitations of the study at various points in the paper, including in the title, and feel that the changes more accurately reflect the 
nature of the study and any implications.

Competing Interests: No competing interests were disclosed.

Reviewer Report 14 September 2021

https://doi.org/10.5256/f1000research.77395.r93064

(C) 2021 Tawiah V. This is an open access peer review report distributed under the terms of the Creative Commons Attribution License, which permits unrestricted use, distribution, and reproduction in any medium, provided the original work is properly cited.

\section{Vincent Tawiah}

DCU Business School, Dublin City University, Dublin, Ireland

This paper addresses an interesting and relevant topic on how online education could solve environmental problems. I suggest the authors improve the paper by considering the following points:

Given that online education covers international activity, I suggest that the authors provide more literature on how international activities affect the environment and then narrow it down to online education. The authors could consider the following papers:

The environmental footprint of China-Africa engagement by Tawiah et al. (2020) ${ }^{1}$; Energy resource melioration and $\mathrm{CO} 2$ emissions in China and Nigeria; Efficiency and trade perspective by Li et al. (2020) 2 .

Policy implication: COVID-19 has forced many HEI to move online; hence, I expect the authors to provide some policy implications on findings nested with the COVID-19 situation. One way is to articulate how online education could reduce emissions and make your studies more relevant in this COVID era.

All the best.

\section{References}

1. Tawiah VK, Zakari A, Khan I: The environmental footprint of China-Africa engagement: An analysis of the effect of China - Africa partnership on carbon emissions.Sci Total Environ. 2021; 756: 143603 PubMed Abstract | Publisher Full Text

2. Li G, Zakari A, Tawiah V: Energy resource melioration and CO2 emissions in China and Nigeria: Efficiency and trade perspectives. Resources Policy. 2020; 68. Publisher Full Text

Is the work clearly and accurately presented and does it cite the current literature? Partly

Is the study design appropriate and is the work technically sound? Yes

Are sufficient details of methods and analysis provided to allow replication by others? 
Yes

If applicable, is the statistical analysis and its interpretation appropriate?

Not applicable

Are all the source data underlying the results available to ensure full reproducibility? Yes

Are the conclusions drawn adequately supported by the results?

Yes

Competing Interests: No competing interests were disclosed.

Reviewer Expertise: Environment

I confirm that I have read this submission and believe that I have an appropriate level of expertise to confirm that it is of an acceptable scientific standard, however I have significant reservations, as outlined above.

Author Response 21 Sep 2021

Richard F Heller, University of Newastle, Newastle, Australia

Reviewer Report

Vincent Tawiah, DCU Business School, Dublin City University, Dublin, Ireland

This paper addresses an interesting and relevant topic on how online education could solve environmental problems. I suggest the authors improve the paper by considering the following points:

Given that online education covers international activity, I suggest that the authors provide more literature on how international activities affect the environment and then narrow it down to online education. The authors could consider the following papers:

The environmental footprint of China-Africa engagement by Tawiah et al. (2020);

Energy resource melioration and $\mathrm{CO} 2$ emissions in China and Nigeria; Efficiency and trade perspective by Li et al. (2020)ㄴ.

Author response: We have added both of these references, and added the following to the Conclusion: "There is a literature on the way in which numerous international economic activities affect the environment 13,14 and the importance of international education to the economy of many countries demonstrates the value of considering how online education might contribute to a reduction in global $\mathrm{CO}_{2}$ emissions. "

Policy implication: COVID-19 has forced many HEI to move online; hence, I expect the authors to provide some policy implications on findings nested with the COVID-19 situation. One way is to articulate how online education could reduce emissions and make your studies more relevant in this COVID era.

Author response: We have added the following to the Conclusion: "The benefits of reducing $\mathrm{CO}_{2}$ emissions through online education for international students should be seen in the context of 
the COVID era, which has demonstrated the importance of online education and the limits to international travel."

All the best.

Author response: Many thanks for your helpful suggestions. We hope that the corrections we have made capture your points.

Competing Interests: No competing interests were disclosed.

The benefits of publishing with F1000Research:

- Your article is published within days, with no editorial bias

- You can publish traditional articles, null/negative results, case reports, data notes and more

- The peer review process is transparent and collaborative

- Your article is indexed in PubMed after passing peer review

- Dedicated customer support at every stage

For pre-submission enquiries, contact research@f1000.com 